\title{
Feasibility Study of the Cranial Implant Fabricated without Supports in Electron Beam Melting
}

\author{
Khaja Moiduddin ${ }^{1, *}$, Syed Hammad Mian ${ }^{1}{ }^{(0}$, Wadea Ameen ${ }^{1}$, Hisham Alkhalefah ${ }^{1}\left(\mathbb{D}\right.$ and Abdul Sayeed ${ }^{2}(\mathbb{D}$ \\ 1 Advanced Manufacturing Institute, King Saud University, Riyadh 11421, Saudi Arabia; \\ smien@ksu.edu.sa (S.H.M.); wqaid@ksu.edu.sa (W.A.); halkhalefah@ksu.edu.sa (H.A.) \\ 2 Department of Mechanical Engineering, College of Engineering, King Saud University, \\ Riyadh 11421, Saudi Arabia; 439106628@student.ksu.edu.sa \\ * Correspondence: khussain1@ksu.edu.sa; Tel.: +966-11-469-7372
}

check for updates

Citation: Moiduddin, K.; Mian, S.H.; Ameen, W.; Alkhalefah, H.; Sayeed, A. Feasibility Study of the Cranial Implant Fabricated without Supports in Electron Beam Melting. Metals 2021, 11, 496. https://doi.org/ $10.3390 /$ met11030496

Academic Editor: Atila Ertas

Received: 22 February 2021

Accepted: 11 March 2021

Published: 17 March 2021

Publisher's Note: MDPI stays neutral with regard to jurisdictional claims in published maps and institutional affiliations.

Copyright: (c) 2021 by the authors. Licensee MDPI, Basel, Switzerland. This article is an open access article distributed under the terms and conditions of the Creative Commons Attribution (CC BY) license (https:/ / creativecommons.org/licenses/by/ $4.0 /)$.

\begin{abstract}
Additive manufacturing (AM), particularly electron beam melting (EBM), is becoming increasingly common in the medical industry because of its remarkable benefits. The application of personalized titanium alloy implants produced using EBM has received considerable attention in recent times due to their simplicity and efficacy. However, these tailored implants are not costeffective, placing a tremendous strain on the patient. The use of additional materials as support during the manufacturing process is one of the key causes of its high cost. A lot of research has been done to lessen the use of supports through various types of support designs. There is indeed a noticeable paucity of studies in the literature that have examined customized implants produced without or minimal supports. This research, therefore, reports on the investigation of cranial implants fabricated with and without supports. The two personalized implants are evaluated in terms of their cost, fabrication time, and accuracy. The study showed impressive results for cranial implants manufactured without supports that cost 39\% less than the implants with supports. Similarly, the implant's (without supports) build time was $18 \%$ less than its equivalent with supports. The two implants also demonstrated similar fitting accuracy with $0.2613 \mathrm{~mm}$ error in the instance of implant built without supports and $0.2544 \mathrm{~mm}$ for the implant with supports. The results indicate that cranial implants can be produced without EBM supports, which can minimize both production time and cost substantially. However, the manufacture of other complex implants without supports needs further study. The future study also requires a detailed review of the mechanical and structural characteristics of cranial implants built without supports.
\end{abstract}

Keywords: electron beam melting; customized implant; cost analysis; fitting accuracy; cranial reconstruction

\section{Introduction}

Craniofacial skeleton injuries that are often induced from tumor, trauma, and external neurosurgical decompression mandate appropriate restoration measures. The purpose of cranial restoration is to provide cerebral protection, preserve esthetics, and relieve neurological symptoms [1]. The performance of cranial or any reconstruction implant relies on the defect's preoperative assessment, the design of the implant, manufacturing approach, and eventually the surgeon's skills and execution. Earlier studies in cranial reconstruction addressed the utilization of computer-aided cranial implant design, although without the usage of medical modeling software and state-of-the-art Additive Manufacturing (AM) technology, resulting in a great deal of manual activities [2,3]. Injection molding [4], extrusion [5], and casting [6] are among the conventional techniques for the fabrication of cranial reconstruction, but they are time-consuming as well as expensive in terms of accuracy and precision.

With the advent of AM techniques in the medical sector and surgical performance over the last decade, greater focus has been given to the manufacture of personalized 
implants. AM allows direct digital manufacturing of patient-specific models with high precision and productivity in surgical preparation for different biomedical applications. $\mathrm{AM}$ also known as three-dimensional (3D) printing, is a processing technique capable of manufacturing complex 3D components by incorporating material layers, beginning with a digital computer-aided design (CAD) model [7]. Metals, polymers, ceramics, composites, and various other materials can be processed using AM technologies. Amongst several metallic biomaterials used in AM, including stainless steel, cobalt-chromium, and titanium alloys. Ti6Al4V ELI (extra-low interstitial) offers enhanced corrosion resistance, high specific strength and young's modulus closer to the bone. Ti6AL4V ELI has a range of advantages over pure titanium (commercial titanium), including greater strength and resistance to fatigue [8]. In addition, Ti6Al4V ELI though being a paramagnetic metal, its magnetic susceptibilities is much lower than that of other biocompatible metals, thus decreasing the influence of magnetic resonance imaging (MRI) and avoiding the hindrance in the diagnosis under MRI.

The integration of clinical imaging, CAD software, and AM has contributed to substantial improvements in surgical and biomedical applications. Electron beam melting (EBM) technology is the primary option for the manufacture of titanium surgical implants among the many AM technologies. EBM has been approved by the FDA (Food and Drug Administration) and Conformité Européene (CE) for the manufacture of medical implants in America and Europe $[9,10]$. EBM produced Ti6Al4V ELI implants exhibits promising results in the fabrication of mandible, hip, orthopedic and cranial implants clinically [11-14]. EBM produces completely dense metallic components, touching 99.9 percent, compared to other metallic AM technologies, which is excellent for biomedical implants [15].

However, the build parts need additional structures (supports) during the EBM fabrication process to assist the overhang surfaces, decrease the geometric distortion and to minimize the warping effect. The sintered powder covering the building component can also act as support structures, thus reducing the cost and time during the construction process. The usage of support structures is appropriate only if the optimum orientation is unable to support the overhang surfaces.

The utilization of support structures in overhang surfaces created using EBM technology was examined by Cheng and Chou [16]. Research suggests that supports increases heat flow and restores thermal behavior as well as decrease overhang deformation [17]. They also serve as the heat dissipaters in high-temperature builds, as in the case of metal based AM [18]. Support structures serve as anchors, assisting in the protection of the part's shape from delamination or deformation during the building process. The anchors are scrapped once the construction is completed. A very thin layer $(40-60 \mu \mathrm{m})$ is melted or sintered by an electron or a laser beam in the powder bed fusion process according to the specified geometry. During the solidification process, considerable thermal gradients and internal stresses are produced, which contributes to distortions and delamination [19]. As a consequence, temporary support material that serves as an anchor dissipates the heat and provides structural resistance to distortions and sagging. The use of support structures in the powder bed fusion process has a number of advantages, but it also has a number of shortcomings [20]. Support removal is usually more difficult in metal-based AM than in the case of polymer-based AM. As of now, there is no established automated procedure to remove the anchors, and are usually detached by the manual procedure. The requirement to produce and then eliminate the attachments leads to a substantial increase in material consumption, costs, energy usage, and total production time.

The existence of support structures certainly presents serious challenges in addition to increasing production time, unnecessary material use, post-processing time in the removal of supports, as well as the danger and challenges of separating the supports without compromising the building portion [21-23]. The presence of support structures has many downsides. After fabrication, the removal of support structures also involves a considerable amount of manual labor. The support structures result in additional expense and time in the milling, cutting, and grinding of the supports [24]. In addition, various types of support 
generate different surface roughness, requiring post-processing. The support structures are of no use once built, because they cannot be recycled when removed and lead to waste materials, thus generating higher material costs [25]. Supports also incur additional energy costs and time of production as well as they are often difficult to remove, particularly for smaller, complicated, and complex geometries [26]. Another problem with support structures is that they are less ideal and inactive relative to usable components. Parts with support structures also influence the surface finish of the build, leaving a mark on the surface after removal [27].

Preferably, the sintered powder serves as a support in the powder bed fusion process, thereby discarding the use of external supports, but depending on the geometry, it is often not enough to support the melted component. By default, the 3D printing software designs the supports in most of the overhang areas. Therefore, reducing the use of unnecessary support structures in overhang sections is extremely necessary. In polymer-based 3D printing, several methods has been used to eliminate them, such as water solvable supports, simple breakaway supports, but in the case of 3D metal printing, it presents a major conundrum [16]. Instead of a continuous mode, Jhabvala et al. [28] reported a revolutionary pulse laser method for the manufacture of support structures and stated that the fabricated supports had similar mechanical properties and were much easier to remove. Similarly, several researchers have studied cellular lattice structures with different support unit cells and investigated their effects on their geometric properties [29,30]. The removal of supports through a feasible orientation in lightweight builds had also been suggested by few researchers [31,32]. Similarly, an experimental analysis involving optimal selfsupporting structures for overhang surfaces was proposed by Calignano [33]. It is of significant relevance, based on literature research, to further study and minimizes the use of support structures in AM wherever applicable. It is evident that a considerable amount of work has been conducted to minimize the use of supports especially by employing different kinds of support designs. Nevertheless, there is a notable lack of literature studies investigating personalized implant build without or limited supports. Consequently, this study focuses on the examination and comparison of cranial implants produced with and without supports. The two personalized implants are evaluated in terms of their cost, fabrication time, and accuracy. The fitting accuracy is assessed to ensure that there is no major deformation in the implant manufactured in the absence of the supports. This is one of the few works in the scientific literature, to the author's knowledge, on the workflow for implant fitting accuracy study and manufacturing of metallic AM cranial implants without supports.

\section{Methodology}

The methodology adopted in this study as shown in Figure 1, consists of four major steps: (1) The creation of an artificial defect in the clean skull, (2) the design of a personalized cranial implant, (3) the manufacture of implants with and without supports, and (4) the evaluation of the implants manufactured.

\subsection{Creation of Artificial Defect}

A clean skull model (Figure 2a) is imported into Materialise Mimics 18.0 (Materialise, $\mathrm{NV}$, Leuven, Belgium) in this study and an unnatural defect with a tumor presumption is produced in the left skull region. Rather than the actual defect, the artificial defect is used to prevent the hassle of obtaining permission from the patient to use their data in the publication. Moreover, as a result of artificial defect, a reference model in the form of a clean skull is available for accuracy assessment. The cutting operation is conducted to split the clean skull (Figure 2a) into two halves (Figure 2b,c), and a region is marked on the left side of the skull to ascertain the tumor outline (Figure 2d). Finally, a void (Figure 2e,f) is generated on the left side of the skull that mimic the defective or affected region. 


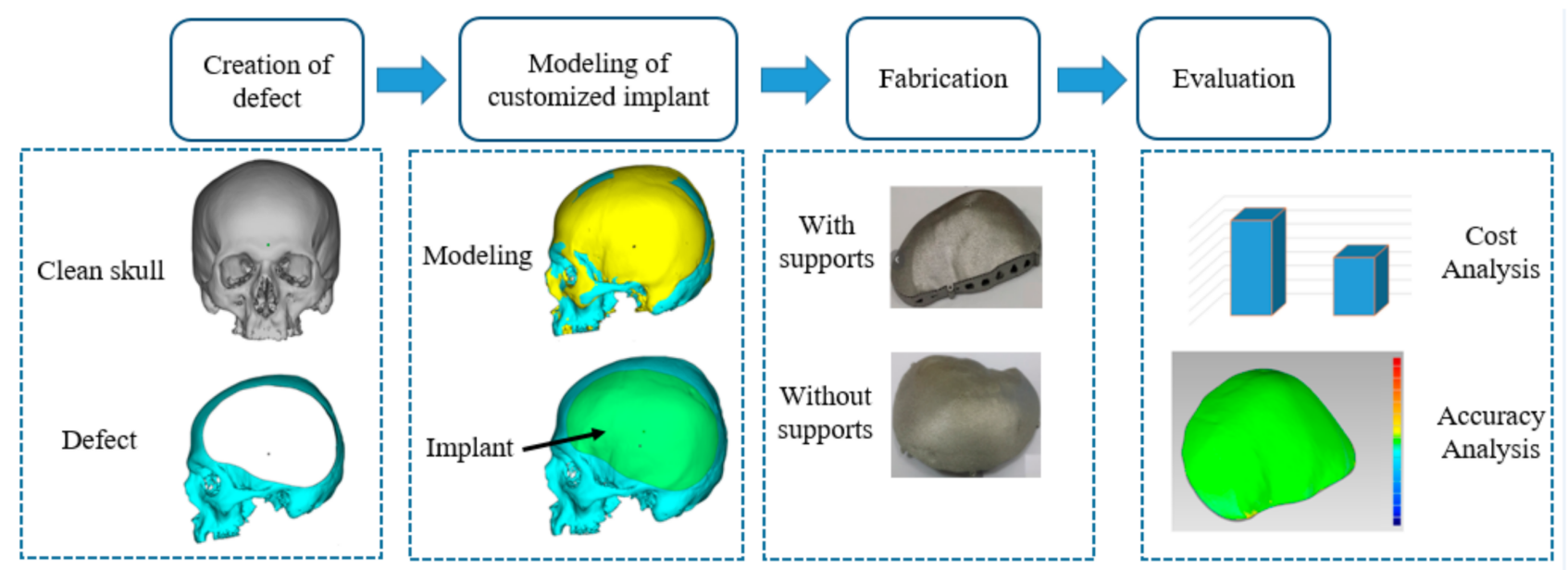

Figure 1. Process flow of adopted methodology.

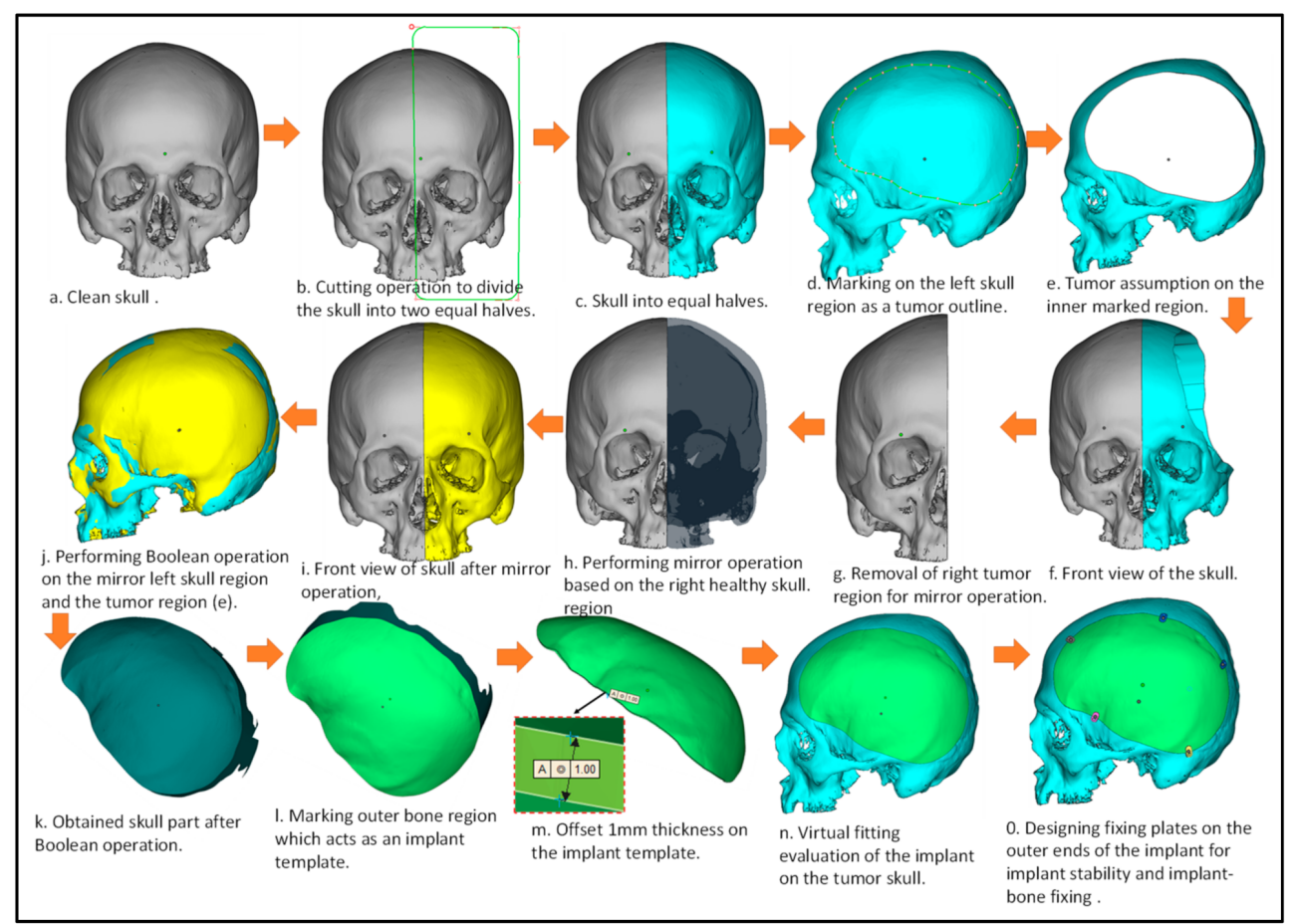

Figure 2. Workflow for the reconstruction of customized cranial implant.

\subsection{Design of Customized Implant}

The mirroring operation is performed based on the healthy right side of skull region. For this purpose, the entire left affected region across the symmetric plane is removed as depicted in Figure 2g. Subsequently, the mirroring operation is implemented to imitate the right healthier side on the left side of the skull (Figure 2h,i). Then, the Boolean subtraction operation is performed on the mirror and tumor assumed model in order to get the implant template (Figure $2 \mathrm{j}, \mathrm{k}$ ). The outer region of the implant template is marked to get the implant outline pattern (Figure 21). An offset thickness of $1 \mathrm{~mm}$ is provided on the pattern to create the final implant design (Figure 2m). Finally, the implant design is evaluated through a virtual fitting on the polymer model (Figure $2 \mathrm{n}$ ) and fixing plates are designed onto the outer ends of the implant to attain implant stability and implant-bone fixing (Figure 2o). 


\subsection{Fabrication}

Upon successful virtual fitting and rehearsal operation, the customized cranial implant and the skull are manufactured using AM technologies. The skull (Figure $3 b$ ) is fabricated using Acryl butadiene Styrene (ABS) material in Zortrax M200 Layer plastic deposition printer (Zortrax, Olsztyn, Poland) (Figure 3a).
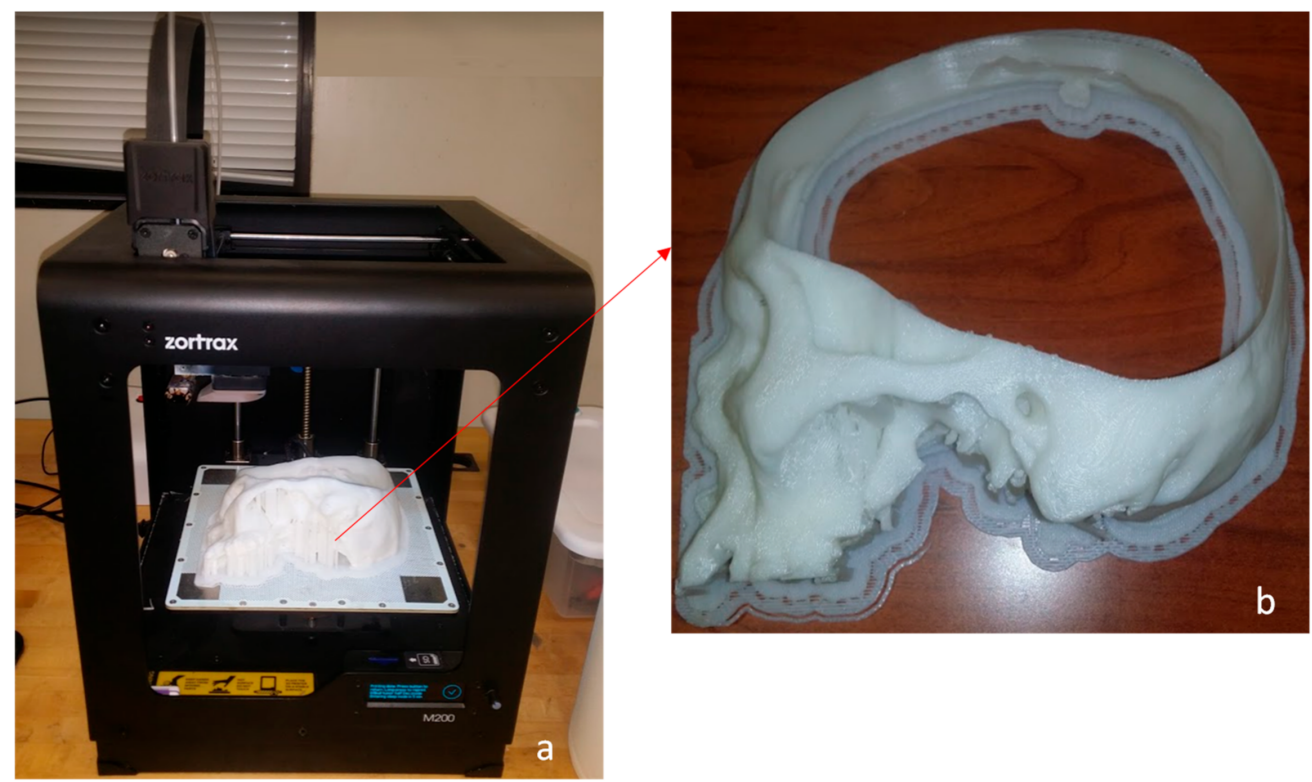

Figure 3. (a) Zortrax additive manufacturing (AM) machine with the fabricated (b) polymer skull.

To generate the support structures, the customized cranial implant design is imported into Magics software (Materialise, NV, Leuven, Belgium). By default, based on the geometry, the software itself generate self-supporting structures onto the overhang parts to prevent deformation and to increase the heat dissipation as shown in the Figure 4.

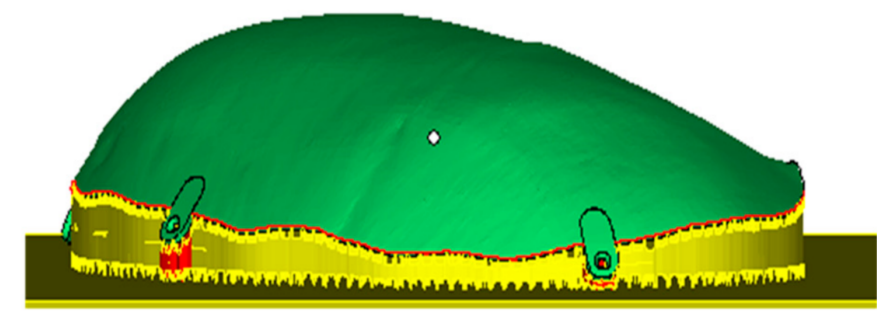

a. Front view of the cranial implant with default block supports

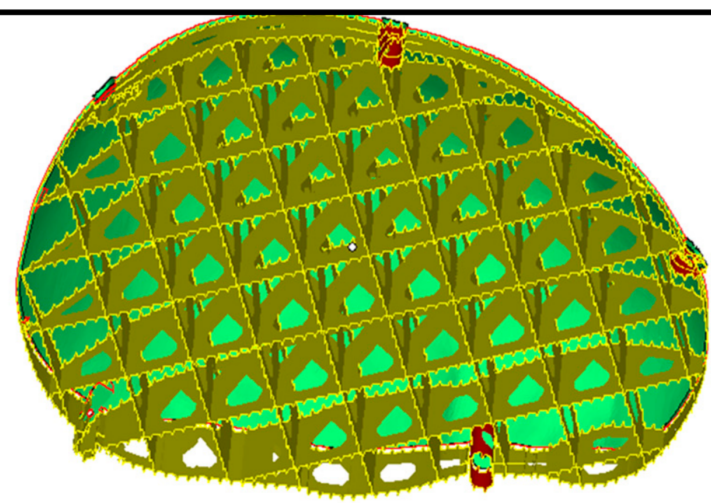

b. Isometric view showing the bottom supports

Figure 4. Virtual simulation of customized cranial implant with default block support structures.

For the fabrication of customized titanium cranial implant one with supports and one without supports, the sliced standard tessellation language (STL) file is loaded into ARCAM EBM following the same orientation. The schematic diagram as illustrated in Figure 5 demonstrates the fabrication process. The metal powder (Ti6Al4V ELI) is loaded and a vacuum is created inside the close build chamber to ensure a clean and controlled environment. The EBM powder layering system equally distributes the powder over the 
powder bed using rake. A powerful $6 \mathrm{KW}$ of high energy electron beam heats and melts the powder bed as per the geometry of the cranial implant. The focus and deflection coils guide the electron beam onto the path for part accuracy. Throughout the build process, the build temperature is kept high at approximately $1000{ }^{\circ} \mathrm{C}$, thus resulting in avoiding residual stresses. After completion of each layer, a new layer of fresh powder is raked over the previous build layer, this process is repeated until the final build is obtained.

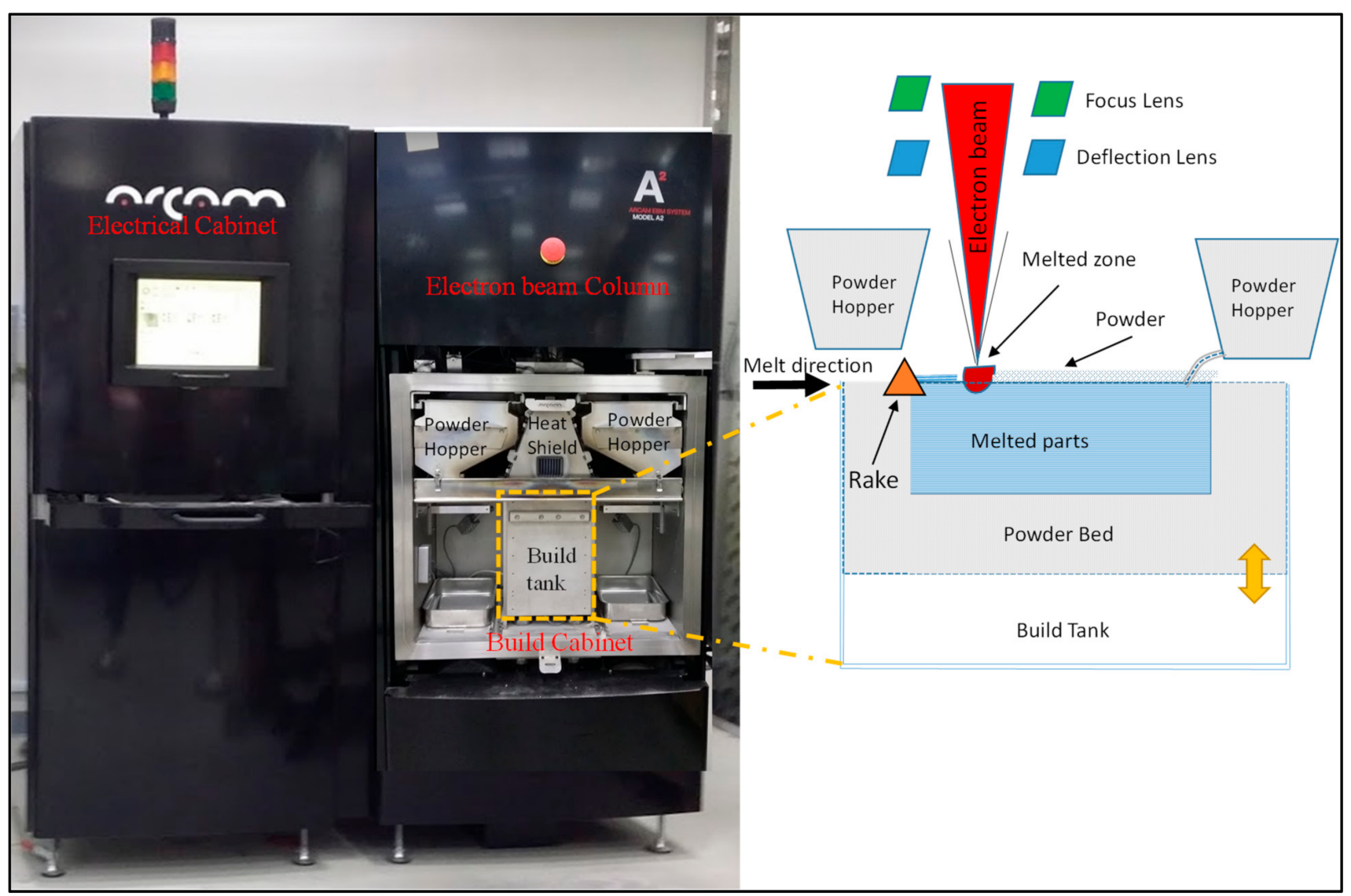

Figure 5. ARCAM's electron beam melting (EBM) machine with schematic diagram illustrating the fabrication process.

Two customized cranial implants are fabricated using EBM, one with default support structures (Figure $6 \mathrm{~d}-\mathrm{f}$ ) and other without supports (Figure 6a-c). Upon completion of final build, the parts are moved to Powder recovery system (PRS) for the removal of semisintered and excess powder attached to the build part. The blasted powder is filtered using sewing machines and recycled for the next job.

The time taken to remove the semi-sintered powder from the implant without support is approximately $5 \mathrm{~min}$, whereas it is around $10 \mathrm{~min}$ for the implant with supports. This may be due to the presence of semi-sintered powder around the supports, which is difficult to blast. The blasted implant (with supports) is then subjected to post processing where the support structures are manually removed using pliers as shown in Figure 7a. Even after supports removal, support protrusions could still be noticed on the cranial implant as illustrated in Figure $7 \mathrm{~b}, \mathrm{c}$. The time taken to remove the supports, including the cleaning of surface protrusion using sandpaper, is almost 100 to $110 \mathrm{~min}$. The post-processed cranial implant is fixed onto the polymer skull model for fitting evaluation as demonstrated in Figure $7 \mathrm{~d}$.

Finally, the cost analysis and fitting evaluation of the two implants are carried out to investigate the implications of support structures. 


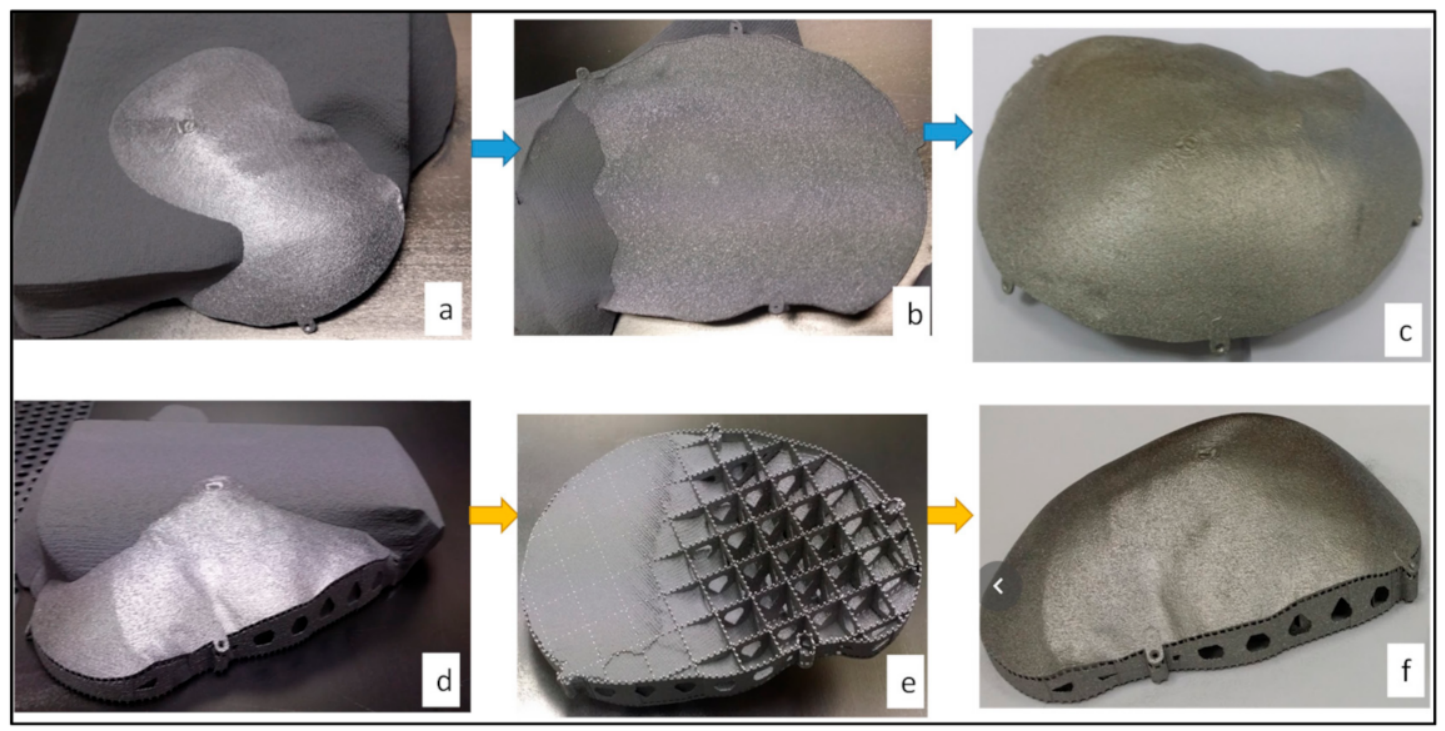

Figure 6. The EBM produced customized cranial implant without supports $(\mathbf{a}-\mathbf{c})$ and implant with support structures (d-f).

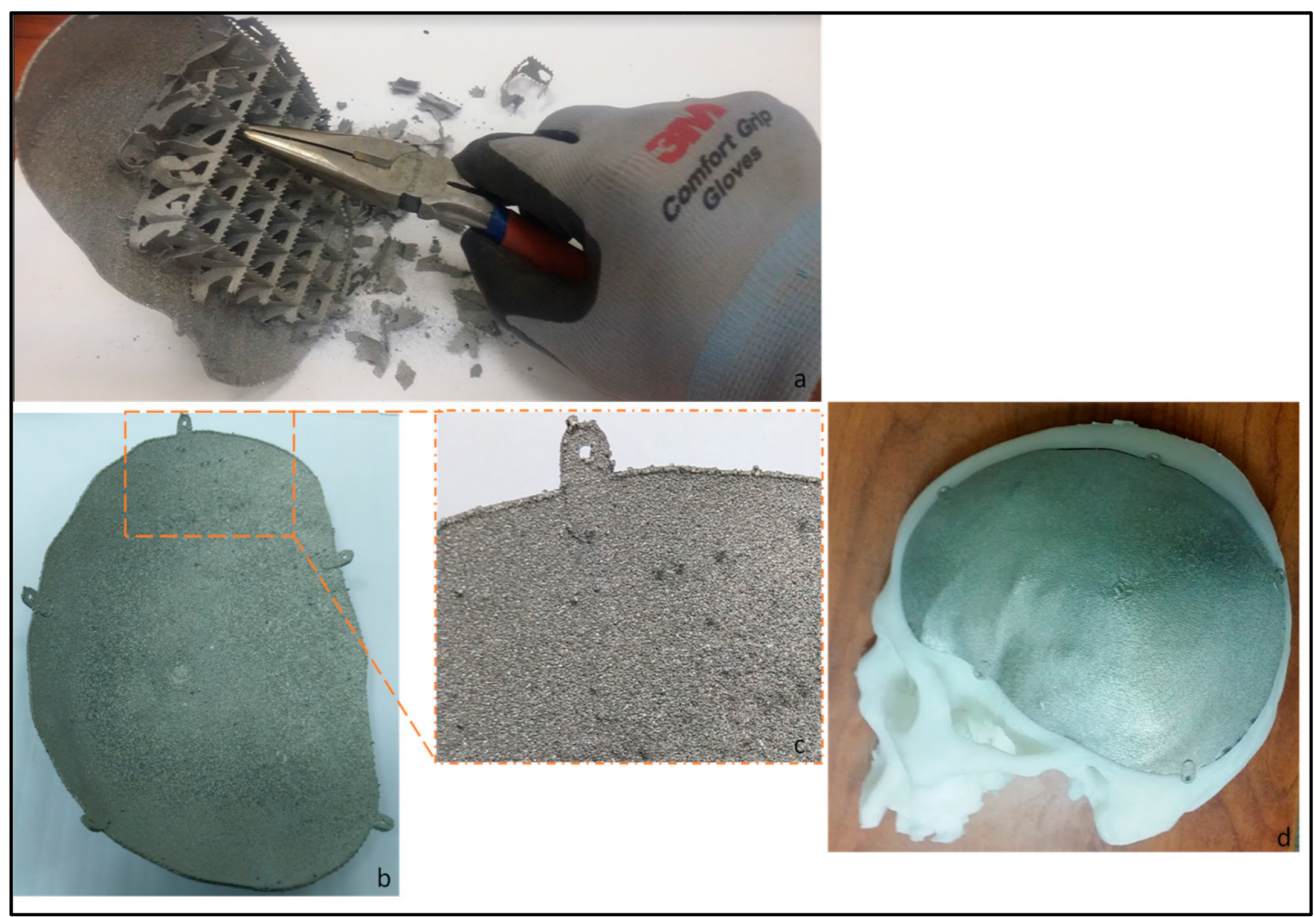

Figure 7. (a) Removal of support structures using pliers, $(\mathbf{b}, \mathbf{c})$ illustration of protrusion onto the surface of the cranial implant after the removal of supports, and (d) implant fitted onto the polymer skull model.

\subsection{Evaluation}

The scanning electron microscopy (SEM) analysis is conducted in order to study the powder size morphology. Figure 8 shows the SEM images of Ti-6Al-4V powder: (a) Low magnification showing the population of particle sizes and (b) high magnification is of an individual powder. This analysis confirms that the formation of the powder particles is primarily spherical in shape with slight variation in the geometry. 


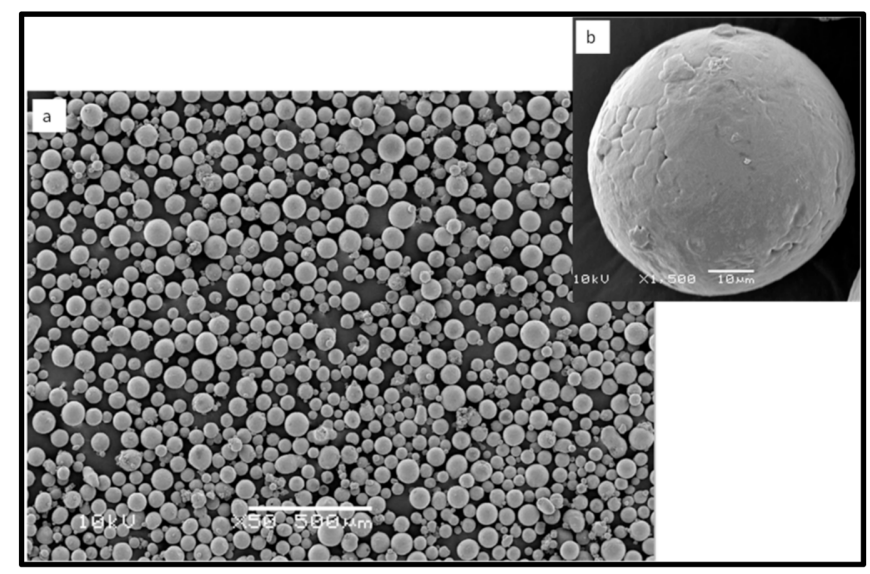

Figure 8. (a) SEM image of Ti-6Al-4V powder particles of different sizes and (b) an individual particle.

A fine powder particle of $50-100 \mu \mathrm{m}$ is used in the EBM process. The EBM build platform and its sintering kinetics between the powder particles are influenced by the size and shape of the powder. Thus, a laser diffraction analysis as shown in Figure 9 is performed to measure and confirm the geometrical dimension of the feedstock powder.

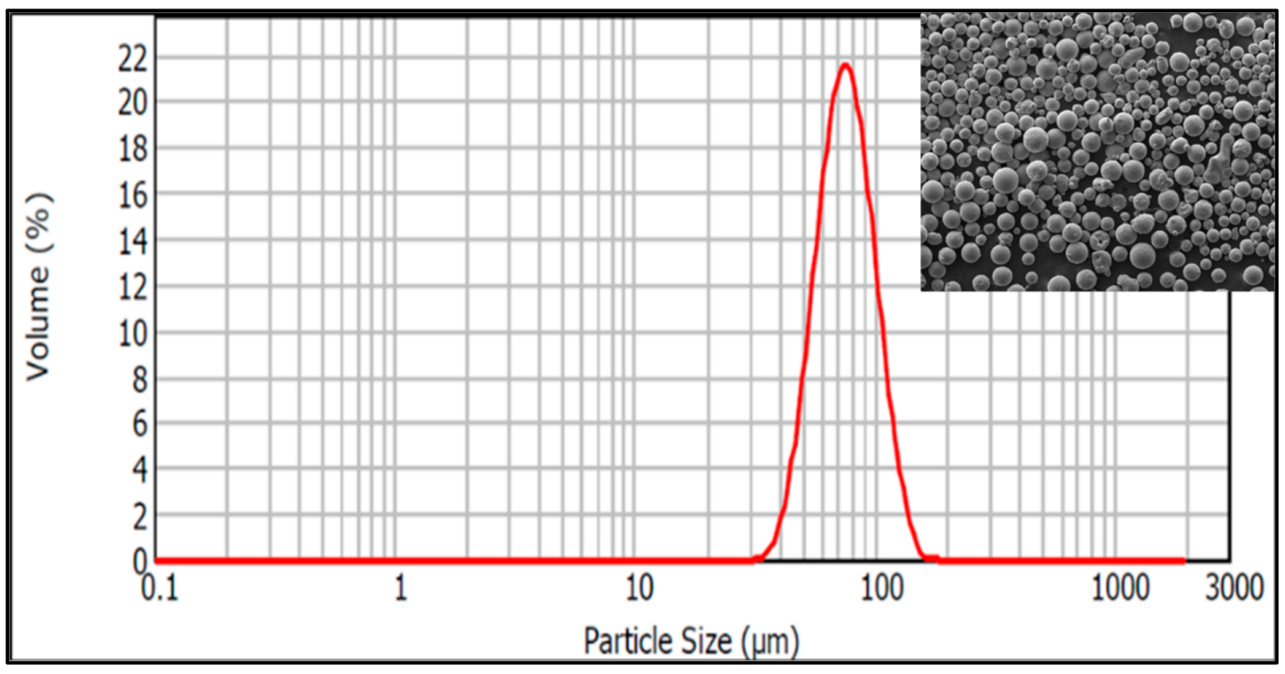

Figure 9. Laser diffraction technique used to study the powder size distribution.

The chemical composition of Ti6Al4V ELI as revealed in Figure 10 is $6.04 \%$ Aluminum (Al), 4.05\% Vanadium (V), 0.013\% Carbon (C), 0.0107\% Iron (Fe), and 0.13\% Oxygen (O), with the remaining constituent as Titanium (Ti) in weight percent. Based on the results, the chemical composition of the EBM build part of Ti6Al4V ELI material do not diverge much from the initial powder feedstock.

\subsubsection{Implant Cost and Time Analysis}

Reliable cost estimation of AM parts is of utmost importance, especially in the medical industry because of the high investment costs related to the product development phases. Moreover, the wrong estimates result in expensive consequences and may result in the production loss. Previous researchers have investigated and developed numerous models for the calculation of AM cost. For example, Ruffo et al. [34] performed a comprehensive cost model study of direct and indirect cost for AM, in which material related cost was considered as a direct cost and the fabrication cost, machine and administration cost were counted as an indirect cost. Similarly, Hopkins and Dickens [35] proposed a comparative 
cost analysis study of three AM processes involving Stereolithography, fused deposition modeling and laser sintering with injection molding. Syam et al. [36] also performed the EBM cost analysis and proved that EBM cost was significantly dependent on the number of units produced in a single fabrication cycle when compared to traditional manufacturing. Lindermann et al. [37] in his study developed a methodology that helped to better understand and analyze the largest cost drivers in the fabrication of metal AM products. Baumers et al. [38] also performed a comparative metal AM study of EBM and selective laser melting based on their cost performance. It is quiet noticeable that previous research done in the AM cost model, mainly focused on the cost structure of the AM product and few on the comparative studies with conventional machining, but there is hardly any study that has considered AM support structures.

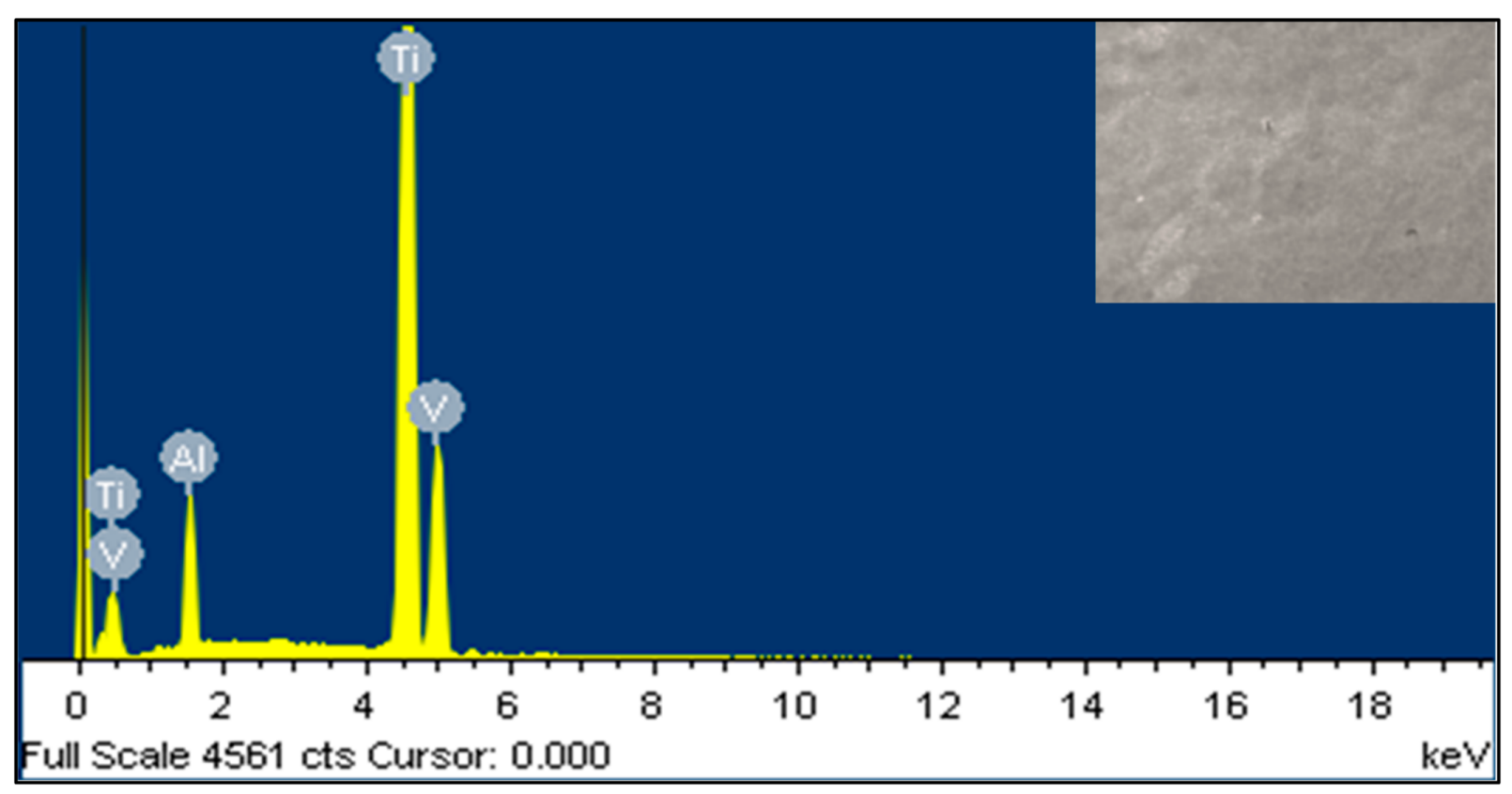

Figure 10. Chemical composition of Ti6Al4V powder used in the implant fabrication.

Henceforth, an inclusive cost and time model developed by Priarone et al. [39] is adopted in this study to investigate the economics of EBM fabricated cranial implants (with supports and without supports). The main driving factors considered in this study are the material consumption, build time and the total cost involved in building the implants. The implemented cost model to estimate the building cost $\left(C_{\text {Build }}\right)$ involves the material cost as well as the energy consumption cost as presented in Equation (1). As shown in Equation (2), the material cost is made up of the price and the consumption of material for each build whereas the energy consumption cost is associated with the cost of running the EBM machine while fabricating cranial implant. Other cost factors such as EBM ownership cost and EBM maintenance cost are not considered, as they remain constant for both cranial implants with and without supports.

$$
\begin{gathered}
\mathrm{C}_{\text {Build }=\text { Material cost }+ \text { Energy consumption cost }} \\
\mathrm{C}_{\text {Build }}=\left[\left(\mathrm{M}_{\text {Consumption }} \times \mathrm{C}_{\text {Raw }}\right)+\left(\mathrm{T}_{\text {Fabrication }} \times \mathrm{E}_{\text {Build }} \times \mathrm{P}_{\text {Energy }}\right)\right]
\end{gathered}
$$

where,

$\mathrm{T}_{\text {Fabrication }}$ : EBM implant fabrication time.

$\mathrm{M}_{\text {Consumption: }}$ Material consumption for the cranial implant in grams.

$C_{\text {Raw }}$ : Cost of the raw material (Ti6Al4V ELI) measured in \$/gram.

$E_{\text {Build }}$ : Energy consumption for the fabrication of cranial implant. 
$P_{\text {Energy: }}$ Price of energy consumption (Electricity cost for EBM process), measured in \$/KWh.

$\mathrm{B}_{\text {Hours }}$ : Build time for the fabrication of cranial implant measured in hh:mm and simplified to hours for multiplication.

$\mathrm{PP}_{\text {Time: }}$ Time taken for post-processing the cranial implant in hh:mm and simplified to hours for multiplication.

$$
\mathrm{T}_{\text {Analysis }}=\left[\mathrm{T}_{\text {Fabrication }}+\mathrm{PP}_{\text {Time }}\right]
$$

Time Analysis $\left(\mathrm{T}_{\text {Analysis }}\right)$ for the fabrication of cranial implant with and without supports includes the time taken to build the cranial implant as well as the post-processing time as explained in Equation (3). The post processing time involves the time taken to remove the semi-sintered powder attached to the implant after build and the removal of supports. Moreover, the weights (in grams) required for the cost model are obtained through the weighing scale (Ohaus Corporation, Parsippany, NJ, USA) as shown in Figure 11.

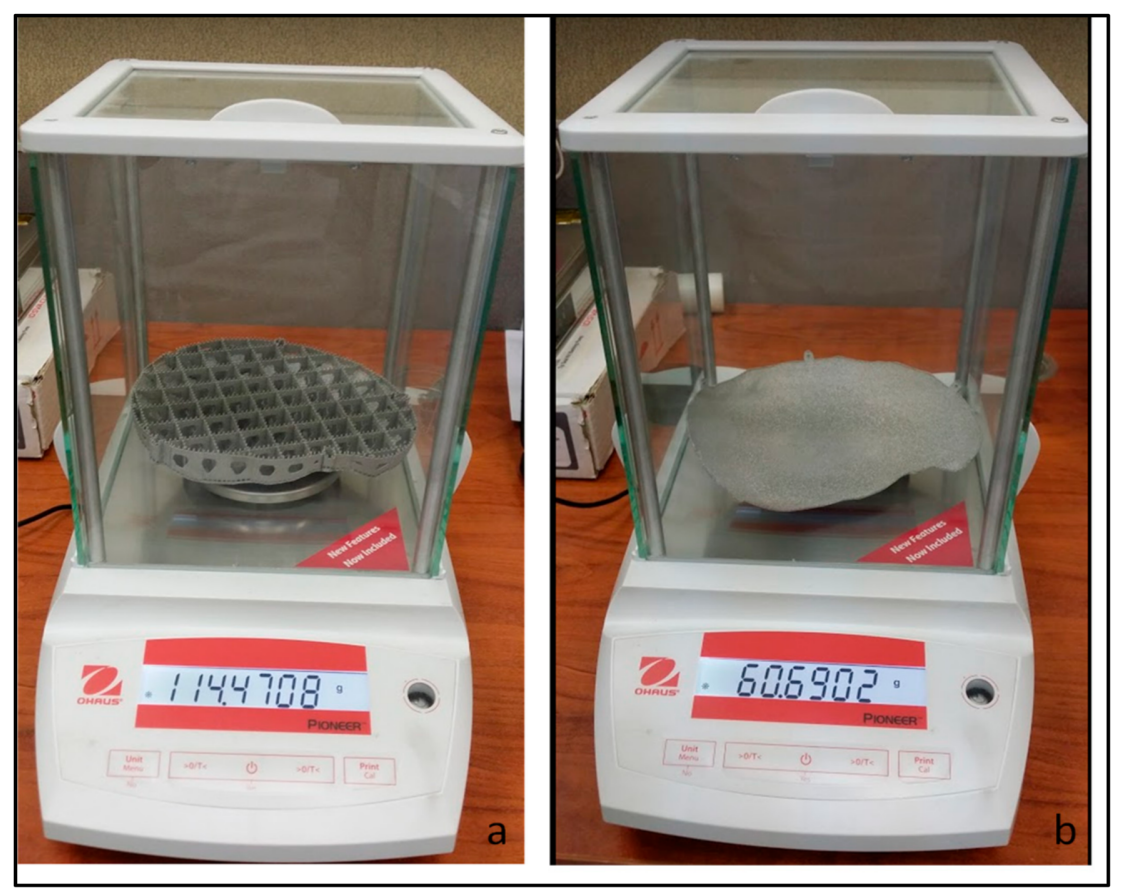

Figure 11. Weighing scale reading of cranial implants (a) with supports and (b) without supports.

\subsubsection{Accuracy Analysis}

The two cranial implants which include the implant manufactured without supports and the implant produced with supports are also inspected for precise fitting. The accuracy assessment is carried out to estimate the gap between the implant and the skull as well as to gauge the consistency of the aesthetics and the external profile of the revived cranium.

In the application of AM technology, model accuracy has a significant impact on surgical planning [40]. Higher accuracy in implant fitting is very important from a medical standpoint, particularly in large cranial defects. Elkatatny and Eldabaa [41] reported that a large proportion of their tumor patients or post-traumatic patients with minor mutilating defects required surgery to improve their aesthetics or cosmetic appearance in addition to providing cerebral protection. If the implant is correctly fitted on the skull, it will have a pleasant cosmetic appearance and the patient will not need to undergo re-surgery. According to Hohne et al. [42], good biocompatibility, adequate defect closure with the precise fitting of the implant reconstruction to the osseous rims, and particularly a pleasing cosmetic outcome are all important elements in cranioplasty. The patient is exposed to all of the risks associated with the repeated surgical operation, including 
those associated with anesthesia [43]. An accurately fabricated implant, according to Toth et al. [44], fits into the defect properly and reduces the likelihood of subsequent movement, dislodgement, and extrusion. Numerous instances of titanium cranioplasty were examined, and it was discovered that the majority of the ill-fitting or aesthetically poor implants resulted in increased intraoperative time and asymmetrical reconstruction [45-47]. The implant possessing an exact match to the patient's cranial defect leads to a very symmetric skull profile and the implant lies passively on the body surface all around the defect. By ensuring a precise fit of the AM-produced implant, Maravelakis et al. [48] reduced roughly $30 \%$ of the overall operation time, thus minimizing intraoperative manipulations to achieve implant fixation.

Figure 12 illustrates the procedure employed to compute the 3D deviation. In this analysis, the defect or tumor is purposely produced in the normal skull and then the healthier right half is replicated on the left faulty portion. The unreal defect is incorporated so that we have the patient's real skull as a guide for comparison thereafter. In the case of the genuine defect, it is not feasible to get a patient's scan (and hence the actual reference) when he/she was healthy. The mirrored model is therefore treated as the reference model in most instances [49]. The utilization of the mirrored model as a reference is not a very reliable approach as it does not incorporate the mirroring bias. In this work, the defect is therefore assumed in the healthier patient to accurately measure the possible error produced in the customized implants. First, the mirrored model is evaluated with the healthy skull of the patient and the overall variance (in the outer direction) is measured. This characterizes the error of mirroring. Next the mirrored model is assessed relative to the virtual cranial implant (because the mirrored model is used as a template to create the implant). This measures the design error of the virtual implant. Finally, the fabricated implants (with and without supports) are examined relative to virtual implants. This gives us the fabrication error. The overall difference in the produced implants can therefore be determined by summing up mirroring, design and manufacturing errors, as shown in Figure 12. In this analysis, $\mathrm{d} 2$ symbolizes the manufacturing error of the cranial implant with support, while $\mathrm{d} 2$ ' denotes the fabrication error of the cranial implant without support. The $\mathrm{d} 3$ is the cumulative error (or the fitting accuracy) of the cranial implant with supports and the $\mathrm{d} 4 \mathrm{implies}$ the total error of the implant without supports.

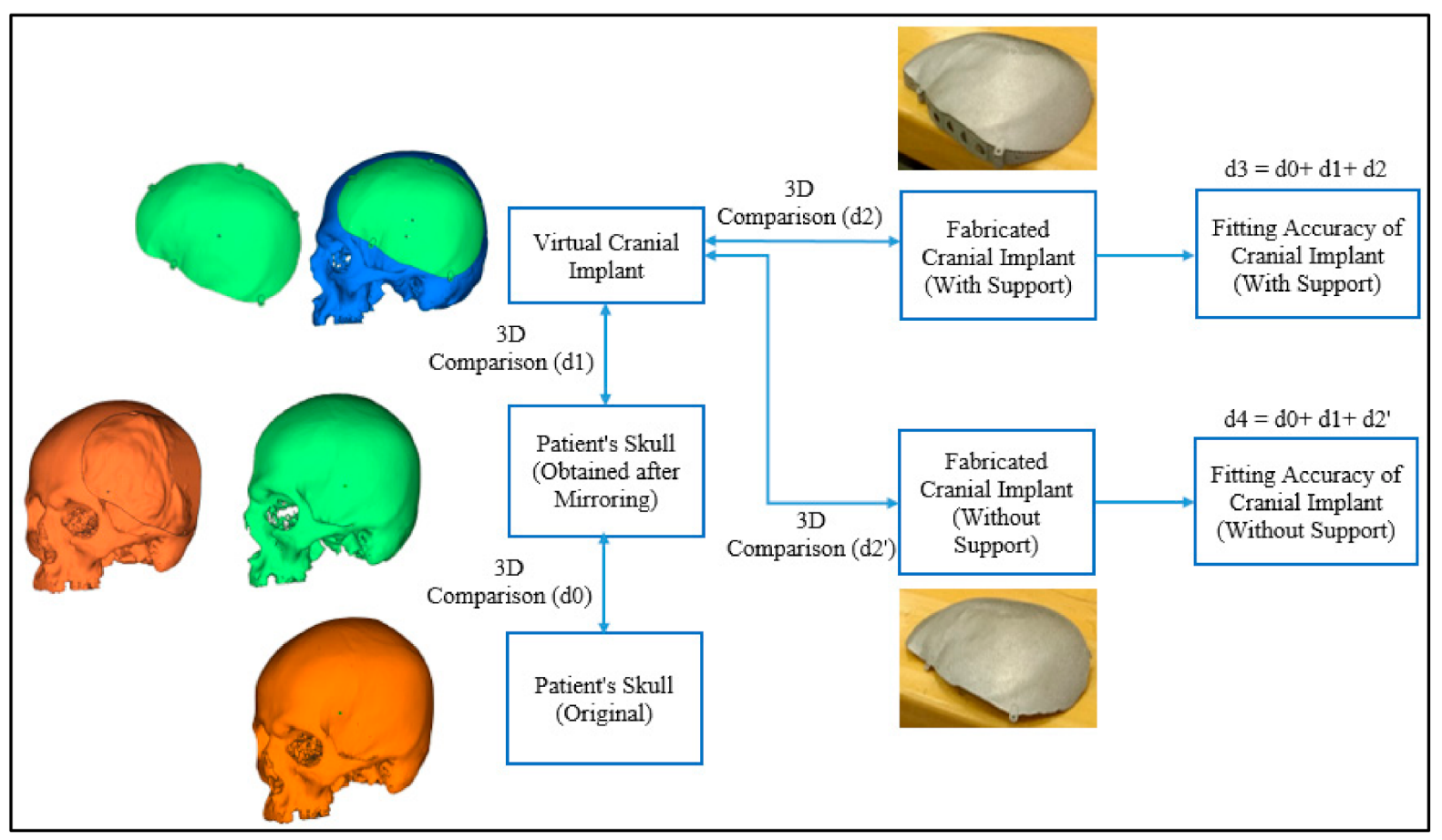

Figure 12. Process flow to assess the accuracy of the cranial implant fitting. 
As shown in Figure 13, the outer surfaces of the fabricated implants are digitized using a laser line scanner mounted on the FARO platinum arm (FARO, Lake Mary, FL, USA). The FARO arm (with laser scanner) is preferred due to its availability, a reasonable precision of $20 \mu \mathrm{m}$ and the ability to acquire a large number of points in short time.

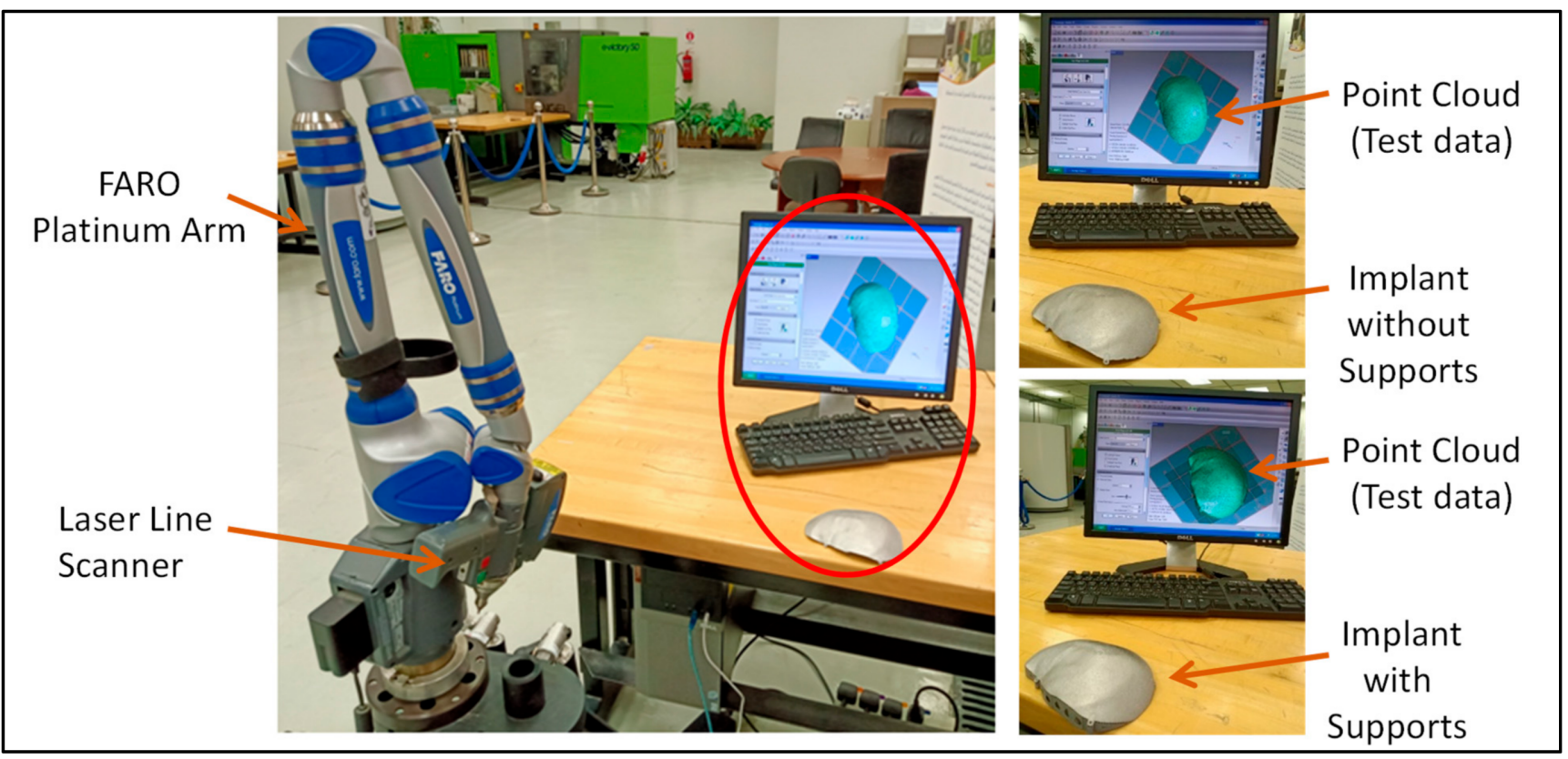

Figure 13. Set up to capture point cloud data for the fabricated models.

The 3D data captured by the FARO scanner is a point cloud that is transformed into triangulation model and then saved in STL after post-processing, using a reverse engineering program (Geomagics Studio 2014, 3D System, Valencia, CA, USA). The "Alignment" feature of the 3D evaluation software (Geomagics Control 2014, 3D System, Valencia, CA, USA) is used with each implant model to superimpose the two datasets (test and reference). In this study, the acquired dataset (of the fabricated implants) is specified as the test model, while the reference is assigned to the virtual (or designed) implant. In Geomagics Control software, the "deviation analysis" algorithm is implemented to conduct a 3D comparison between the reference and test models. To demonstrate the variations in the test models, a graphic of color scales is generated. The results are determined on the basis of almost 100,000 points on the 3D scanned model. The "average error" between each pair, described as the average of all the distances between the closest point pairs on the reference and the test model, is estimated. The closest point pairs are searched and matched automatically by the software algorithm.

\section{Results and Discussion}

The cost and time analysis results are illustrated in Tables 1 and 2 respectively. Figure 14a indicates, that the material consumption decreases significantly by $47 \%$ from $125.92 \mathrm{~g}$ to $66.75 \mathrm{~g}$ in the case of the implant without supports. Thus, the material consumed in the manufacture of cranial implants with supports is almost double that of the cranial implant without supports. The higher material consumption in turn raises the final cost of the cranial implant with support in comparison to the implant without supports. The cranial implant without supports costs roughly $\$ 21$ in comparison to $\$ 34$ for the implant with supports, thereby resulting in a $39 \%$ reduction in overall cost (Figure 14b). 
Table 1. Cost estimation for the EBM build cranial implants.

\begin{tabular}{|c|c|c|c|}
\hline Influencing Factors & Description & Values & Estimation \\
\hline \multirow{5}{*}{$\begin{array}{l}\text { Material consumption (grams) } \\
\mathrm{M}_{\text {Consumption }}\end{array}$} & $\begin{array}{l}\text { Weight of implant with } \\
\text { supports }\end{array}$ & $114.47 \mathrm{~g}$ & \\
\hline & $\begin{array}{l}\text { Weight of Implant without } \\
\text { supports }\end{array}$ & $60.69 \mathrm{~g}$ & \\
\hline & $\begin{array}{l}\text { Material wastage including } \\
\text { support structures [50] }\end{array}$ & $10 \%$ of built mass & \\
\hline & $\begin{array}{c}\mathrm{M}_{\text {consumption }} \text { (Material } \\
\text { consumed for cranial implant } \\
\text { with supports) }\end{array}$ & $125.91 \mathrm{~g}$ & $\begin{array}{c}\text { Total mass of EBM built implant }= \\
\text { (Implant mass }+10 \% \text { material } \\
\text { wastage of built mass })= \\
114.47+11.44\end{array}$ \\
\hline & $\begin{array}{c}\mathrm{M}_{\text {consumption }} \text { (Material } \\
\text { consumed for cranial implant } \\
\text { without supports) }\end{array}$ & $66.75 \mathrm{~g}$ & $60.69+6.06$ \\
\hline Material cost (per gram) & $\mathrm{C}_{\text {Raw }}$ (Ti6Al4V ELI cost price) & $\$ 0.22 / \mathrm{g}$ & $=\$ 220 / \mathrm{kg}$ \\
\hline$\left(\mathrm{M}_{\text {consumption }} \times \mathrm{C}_{\text {Raw }}\right)$ Supports & Implant with supports & $\$ 27.70$ & $(125.91 \mathrm{~g} \times \$ 0.22 / \mathrm{g})$ \\
\hline $\begin{array}{c}\left(\left(\mathrm{M}_{\text {consumption }} \times \mathrm{C}_{\mathrm{Raw}}\right) \text { Without }\right. \\
\text { supports }\end{array}$ & Implant without supports & $\$ 14.68$ & $(66.75 \mathrm{~g} \times \$ 0.22 / \mathrm{g})$ \\
\hline \multirow[t]{5}{*}{$\begin{array}{l}\mathrm{T}_{\text {Fabrication (cranial implants }} \\
\text { with supports) }\end{array}$} & $\begin{array}{l}\text { Time to obtain desired } \\
\text { vacuum level }\end{array}$ & $0: 3 \mathrm{hh}: \mathrm{mm}$ & \\
\hline & Time to heat start plate & 0:45 hh:mm & \\
\hline & EBM cool down time & 4:00 hh:mm & \\
\hline & $\begin{array}{l}\text { Build time for cranial implant } \\
\text { with supports }\end{array}$ & 5:39 hh:mm & \\
\hline & $\begin{array}{c}\mathrm{T}_{\text {Fabrication }} \\
\text { Time for completion of cranial } \\
\text { build with supports }\end{array}$ & $10.9 \mathrm{~h}$ & $\begin{array}{c}\text { Time for desired vacuum level + } \\
\text { heating start plate }+ \text { EBM cool } \\
\text { down time + part build time } \\
(0: 30+0: 45+4: 00+5: 39)=10: 54 \\
\text { hh:mm }=10.9 \mathrm{~h}\end{array}$ \\
\hline \multirow[t]{2}{*}{$\begin{array}{l}\mathrm{T}_{\text {Fabrication }} \text { (cranial implants } \\
\text { without supports) }\end{array}$} & $\begin{array}{l}\text { Build time for cranial implant } \\
\text { without supports }\end{array}$ & 5.11 hh:mm & \\
\hline & $\begin{array}{c}\mathrm{T}_{\text {Fabrication }} \\
\text { Time for completion of cranial } \\
\text { build without supports }\end{array}$ & $10.43 \mathrm{~h}$ & $\begin{array}{c}\text { Time for desired vacuum level + } \\
\text { heating start plate + EBM cool } \\
\text { down time + part build time } \\
(0: 30+0: 45+4: 00+5: 11)=10: 26 \\
\text { hh:mm }=10.43 \mathrm{~h}\end{array}$ \\
\hline $\mathrm{T}_{\text {Fabrication }}$ (with supports) & Implant with support & $10.90 \mathrm{~h}$ & \\
\hline $\mathrm{T}_{\text {Fabrication }}$ (without supports) & Implant without support & $10.43 \mathrm{~h}$ & \\
\hline $\begin{array}{c}\text { EBM energy consumption (KW) } \\
\text { for Implant fabrication } \\
\text { E }_{\text {Build }}\end{array}$ & EBM Power supply & $7 \mathrm{KW}[51]$ & \\
\hline $\begin{array}{l}\text { EBM Electricity cost (Per hour) } \\
\qquad P_{\text {Energy }}\end{array}$ & $\begin{array}{l}P_{\text {Energy }}(\text { EBM energy } \\
\text { consumption cost) }\end{array}$ & $\$ 0.085 / \mathrm{KWh}$ & $\begin{array}{c}\text { Electricity tariff }=\text { SAR } \\
\text { 0.32/KWh(https: / / www.se.com. } \\
\text { sa/en-us/customers / Pages / } \\
\text { TariffRates.aspx (accessed on } 18 \\
\text { August 2020)) } \\
\text { Conversion of SAR to } \$= \\
\$ 0.085 / \text { KWh }\end{array}$ \\
\hline
\end{tabular}


Table 1. Cont.

\begin{tabular}{|c|c|c|c|}
\hline Influencing Factors & Description & Values & Estimation \\
\hline $\begin{array}{l}\mathrm{E}_{\text {Build }} \times \mathrm{T}_{\text {Fabrication }} \text { (with } \\
\text { supports }) \times \mathrm{P}_{\text {Energy }}\end{array}$ & Cranial implant with supports & $\$ 6.48$ & $\begin{array}{c}=(\text { EBM power consumption } x \\
\text { EBM build time for cranial } \\
\text { implant with supports } x \text { EBM } \\
\text { energy consumption cost })=7 \mathrm{KW} \\
\times 10.9 \text { hours }^{\prime} \times \$ 0.085 / \mathrm{KWh}\end{array}$ \\
\hline $\begin{array}{c}\mathrm{E}_{\text {Build }} \times \mathrm{T} \\
\text { Fabrication } \\
\text { (without supports) } \times \mathrm{P}_{\text {Energy }}\end{array}$ & $\begin{array}{l}\text { Cranial implant without } \\
\text { supports }\end{array}$ & $\$ 6.20$ & $=7 \mathrm{KW} \times 10.43 \mathrm{~h} \times \$ 0.085 / \mathrm{KWh}$ \\
\hline \multirow[t]{2}{*}{ Total Cost for building implant } & Implant with supports & $\$ 34.18$ & $\begin{array}{c}(\text { material cost }+ \text { Energy } \\
\text { consumption cost })= \\
\$ 27.70+\$ 6.48\end{array}$ \\
\hline & Implant without support & $\$ 20.88$ & $=\$ 14.68+\$ 6.20$ \\
\hline Percentage Difference in cost & & $39 \%$ & $=(13.3 / 34.18) \times 100$ \\
\hline
\end{tabular}

Table 2. Time analysis for fabrication of cranial implant with and without supports.

\begin{tabular}{|c|c|c|c|}
\hline Factors & Description & Values & Estimation \\
\hline \multirow{2}{*}{ Build Time (Hours) } & $\begin{array}{l}\text { B }_{\text {Hours }} \text { (Build Hours for } \\
\text { Cranial Implant with } \\
\text { Supports) }\end{array}$ & 10:54 hh:mm & $\begin{array}{l}\text { Time Taken for the Fabrication of } \\
\text { Cranial Implant with Supports- }(0: 3+ \\
0: 45+4: 00+5: 39)=10: 54 \text { hh:mm }\end{array}$ \\
\hline & $\begin{array}{l}\text { B Hours } \\
\text { Cranial Implant without } \\
\text { Supports) }\end{array}$ & 10:26 hh:mm & $\begin{array}{c}=(0: 3+0: 45+4: 00+5: 11) \\
=10: 26 \text { hh:mm }\end{array}$ \\
\hline \multirow{2}{*}{$\begin{array}{c}\text { EBM Post-Processing Time } \\
\text { (Hours) } \\
\text { PP }_{\text {Time }}\end{array}$} & $\begin{array}{l}\text { Post processing time for } \\
\text { implant with supports }\end{array}$ & 1:55 hh:mm & $\begin{array}{l}\text { Post processing time includes the } \\
\text { removal of supports + removal of } \\
\text { semi-centered powder } \\
(1: 45+0: 10) \text { hh:mm }\end{array}$ \\
\hline & $\begin{array}{l}\text { Post processing time for } \\
\text { implant without supports }\end{array}$ & 0:05 hh:mm & Removal of semi-centered powder. \\
\hline \multirow{2}{*}{$\begin{array}{l}\text { Total Build time for Cranial } \\
\text { implant }\end{array}$} & $\begin{array}{l}\text { Total build time for cranial } \\
\text { implant with support after } \\
\text { post-processing }\end{array}$ & 12:49 hh:mm & $\begin{array}{c}\text { Total Build time }=(\text { fabrication time }+ \\
\text { post-processing time }) \\
(10: 54+1: 55) \text { hh:mm } \\
=12: 49 \mathrm{hh}: \mathrm{mm}=12.81 \mathrm{~h}\end{array}$ \\
\hline & $\begin{array}{l}\text { Total build time for cranial } \\
\text { implant without support after } \\
\text { post-processing }\end{array}$ & 10:31 hh:mm & $(10: 26+0: 05)$ hh:mm \\
\hline $\begin{array}{l}\text { Percentage difference in build } \\
\text { time }\end{array}$ & & $18 \%$ & $\begin{aligned} & =(12: 49-10: 31) \\
= & 2: 18 \mathrm{hh}: \mathrm{mm}(2.30 \mathrm{~h}) \\
= & (2.30 / 12.81) \times 100\end{aligned}$ \\
\hline
\end{tabular}

As indicated in Table 2, the cranial implant with support structures take approximately $10 \mathrm{~min}$ for sandblasting the semi-sintered powder and $1 \mathrm{~h} 45 \mathrm{~min}$ for the support's removal. Removing support structures is a tedious and time-consuming process and additional precautions should be taken to prevent implant damage. The time taken for post-processing of unsupported cranial implant is just $5 \mathrm{~min}$, which is the removal of semi-sintered powder. The difference in time between the implant with and without supports in the removal of semi-sintered powder is primarily due to the extra time required to remove the concealed powder within the supports. The building time for implants without supports is $18 \%$ shorter than for implants with supports (Figure 14c). 


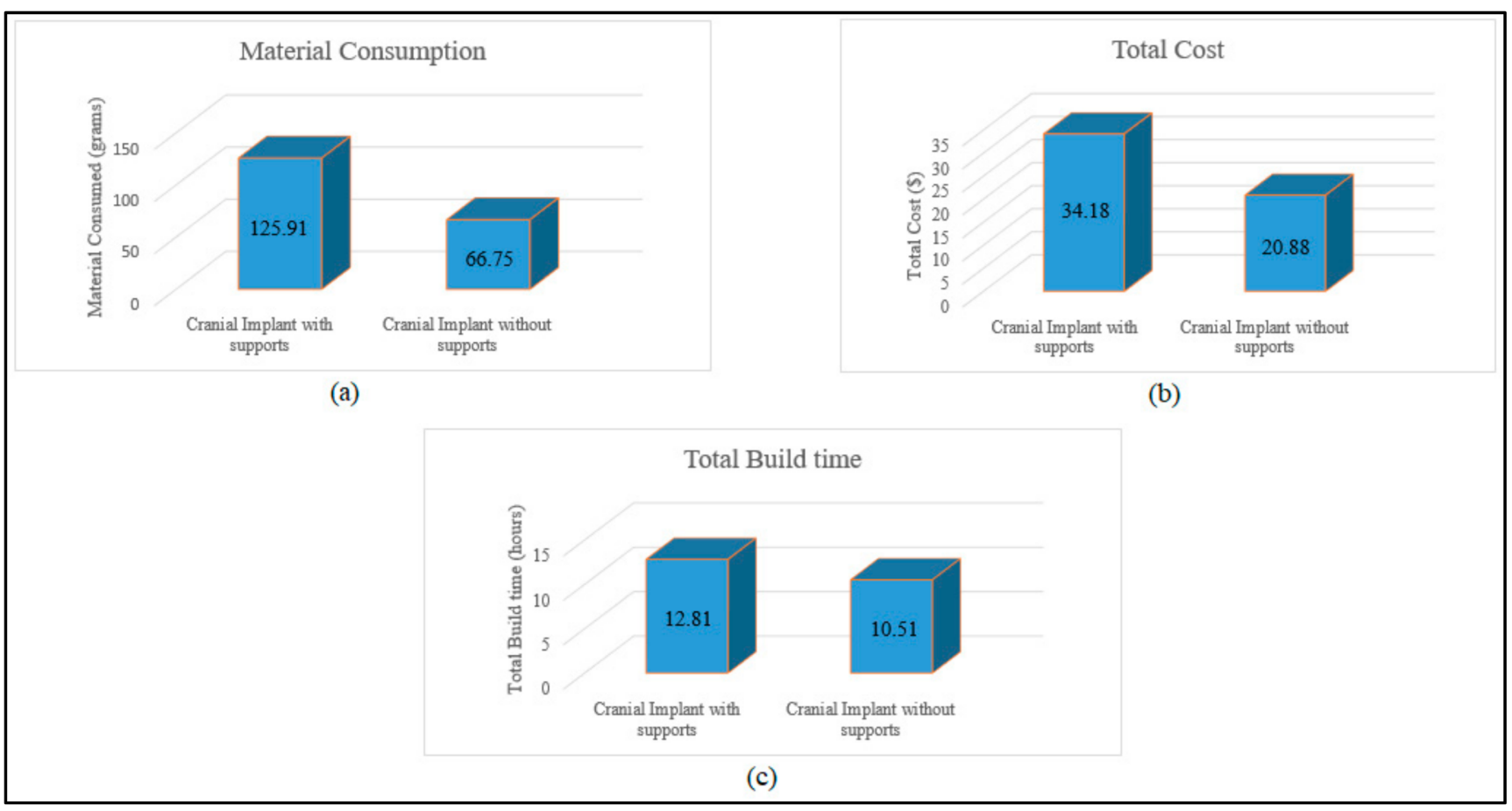

Figure 14. Comparative analysis of cranial implants with and without supports (a) material consumption; (b) total cost; and (c) total build time.

It is apparent from the cost and time analysis that, if the support structures are not used, a considerable amount of time and cost could be saved. The user often implements support mechanisms due to normal protocol, or default settings. Certainly, there is always the likelihood that some sections can be constructed effectively in EBM without the supports. The current investigation, for instance, has demonstrated that the cranial implant is successfully built without support structures. Significant costs, time, and effort needed to withdraw supports (during post-processing) are saved. There are, however, many components that cannot be fabricated without supports, either because of their complexity, size, or shape. In these cases, users must at least try to reduce support by defining the critical support locations or through applying various types of support design. There is always a risk that due to the lack of support, the fitting accuracy of the implant could be compromised. Henceforth, a detailed fitting accuracy analysis for the two implants is also carried out in this investigation.

Table 3 presents the findings of 3D deviation analysis ( $\mathrm{d} 0, \mathrm{~d} 1, \mathrm{~d} 2, \mathrm{~d} 2^{\prime}, \mathrm{d} 3$, and $\left.\mathrm{d} 4\right)$ in terms of average deviations. The visual deviation is also shown in Figure 15, including a color-coded map to display the variations between each test model and the reference. It is noted that the greener the color, the nearer the reference model is to it.

Table 3. Outcome of 3D deviation analysis.

\begin{tabular}{ccc}
\hline Models Combination & Notations & Deviation (mm) \\
\hline Original (Reference) and Mirroring (Test) & $\mathrm{d} 0$ & 0.1458 \\
\hline Mirroring (Reference) and Virtual Implant (Test) & $\mathrm{d} 1$ & 0.0182 \\
\hline Virtual Implant (Reference) and Fabricated & $\mathrm{d} 2$ & 0.0904 \\
\cline { 2 - 3 } Implant with Supports (Test) & $\mathrm{d} 3$ & 0.2544 \\
\hline $\begin{array}{c}\text { Virtual Implant (Reference) and Fabricated } \\
\text { Implant without Supports (Test) }\end{array}$ & $\mathrm{d} 2^{\prime}$ & 0.0973 \\
\hline
\end{tabular}




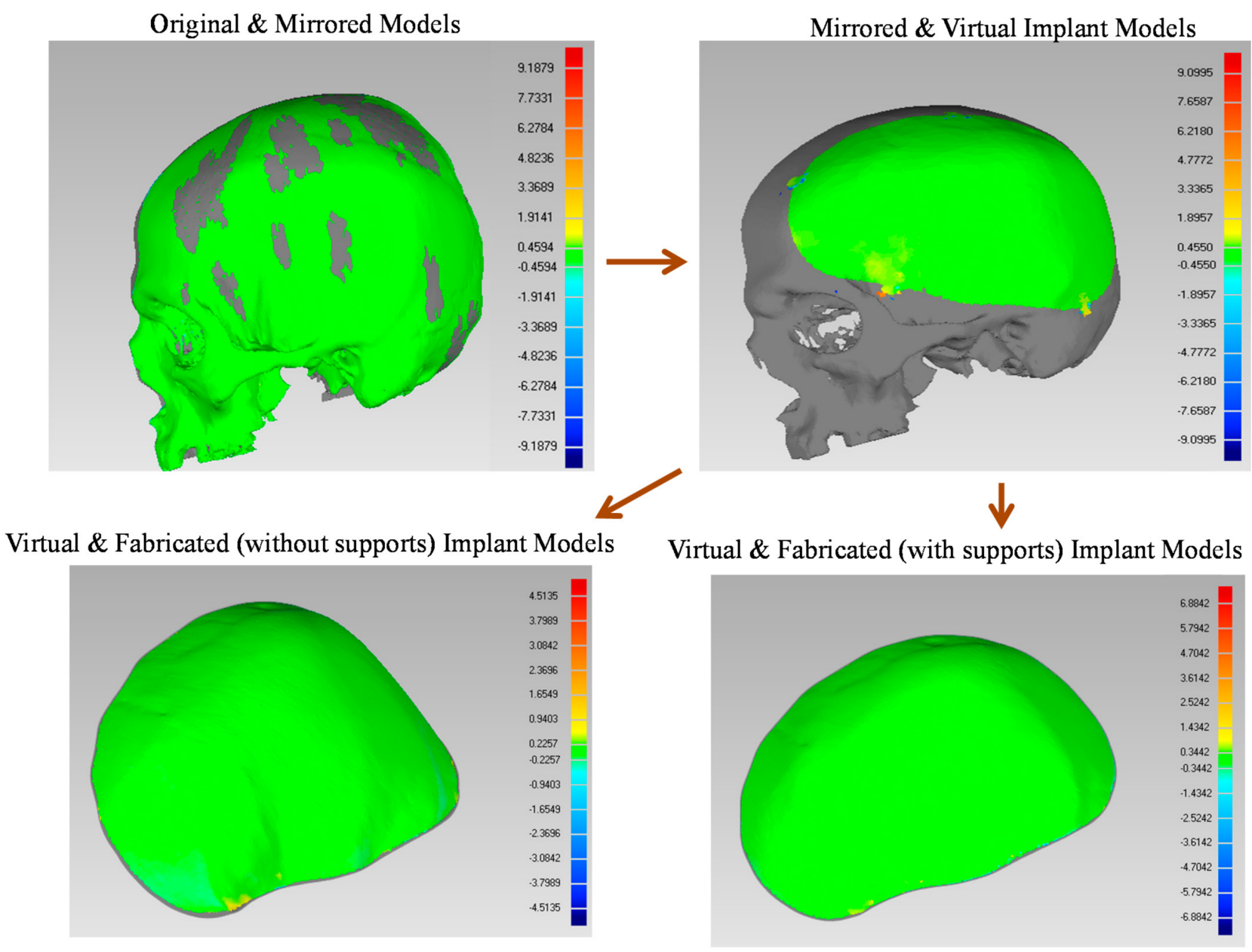

Figure 15. Graphical display of 3D deviation analysis.

The specimens display similar variations from the reference, according to Figure 15, and the implant with support presents a slightly better result, with a lower variance from the reference. The divergence is, however, negligible between implants with support and without support. This is a difference of less than $3 \%$, which is quite marginal. The average cumulative implant error (without support) with respect to the original skull of the patient is $0.2613 \mathrm{~mm}$, whereas that with support is $0.2544 \mathrm{~mm}$.

\section{Conclusions}

This has been a recognized fact that conventional cranial reconstruction techniques are ineffective because they cannot handle customization effectively. Therefore, the EBM is progressively being employed in the domain of implant reconstruction due to its efficacy and performance. Nevertheless, the manufacture of EBM entails higher costs and greater production time, which makes it expensive for the general populace. It can be stated from the cost analysis that the material cost and the machine running cost are the one that contributes substantially to the total implant cost. It has also been noted that a larger amount of material used as supports results in higher production time, making the manufacture of implants using EBM very costly. In addition, the EBM produced implant without supports must be examined for fitting accuracy to preserve the outer appearance and attain the desired aesthetics. The cost analysis illustrates significant improvements for non-support cranial implants as they cost 39\% less than the implant with supports. Likewise, the implant's production time (without support) is found to be $18 \%$ shorter than its equivalent implant with supports. The two implants also display similar fitting accuracy with $0.2613 \mathrm{~mm}$ error in the instance of implant fabricated without supports and $0.2544 \mathrm{~mm}$ 
for the implant with supports. The study thus found that the cranial implants can be manufactured without EBM supports, which can dramatically reduce both manufacturing time and cost expenses. However, more study is needed to produce other complex implants in the absence of supports. The future research also aims to include a thorough examination of the mechanical and structural aspects of cranial implants without supports.

Author Contributions: Conceptualization, K.M., S.H.M., and W.A.; methodology, K.M., S.H.M., and W.A.; validation, K.M., S.H.M., and H.A.; formal analysis, K.M., S.H.M., and A.S.; investigation, K.M., S.H.M., H.A., and A.S.; data curation, W.A., and H.A.; writing-original draft preparation, K.M. and S.H.M.; writing—review and editing, K.M., S.H.M., W.A., H.A., and A.S.; Project administration, K.M. All authors have read and agreed to the published version of the manuscript.

Funding: This research was financially supported by Deanship of Scientific Research, King Saud University: Research group No. RG-1440-034.

Institutional Review Board Statement: Not applicable.

Informed Consent Statement: Written informed consent has been obtained from the subject to publish this paper.

Acknowledgments: The authors extend their appreciation to the Deanship of Scientific Research at King Saud University for funding this work through Research group no RG-1440-034.

Conflicts of Interest: The authors declare no conflict of interest.

\section{References}

1. van de Vijfeijken, S.E.C.M.; Münker, T.J.A.G.; Spijker, R.; Karssemakers, L.H.E.; Vandertop, W.P.; Becking, A.G.; Ubbink, D.T. CranioSafe group autologous bone is inferior to alloplastic cranioplasties: Safety of autograft and allograft materials for cranioplasties, a systematic review. World Neurosurg. 2018, 117, 443-452. [CrossRef]

2. Kim, B.; Hong, K.-S.; Park, K.-J.; Park, D.-H.; Chung, Y.-G.; Kang, S.-H. Customized cranioplasty implants using three-dimensional printers and polymethyl-methacrylate casting. J. Korean Neurosurg. Soc. 2012, 52, 541-546. [CrossRef]

3. Unterhofer, C.; Wipplinger, C.; Verius, M.; Recheis, W.; Thomé, C.; Ortler, M. Reconstruction of large cranial defects with Poly-Methyl-Methacrylate (PMMA) using a rapid prototyping model and a new technique for intraoperative implant modeling. Neurol. Neurochir. Pol. 2017, 51, 214-220. [CrossRef]

4. Chang, S.C.N.; Tobias, G.; Roy, A.K.; Vacanti, C.A.; Bonassar, L.J. Tissue engineering of autologous cartilage for craniofacial reconstruction by injection molding. Plast. Reconstr. Surg. 2003, 112, 793-799, discussion 800-801. [CrossRef]

5. Brown, A.E.; Banks, P. Late extrusion of alloplastic orbital floor implants. Br. J. Oral Maxillofac. Surg. 1993, 31, 154-157. [CrossRef]

6. Wolfaardt, J.F.; Coss, P. An impression and cast construction technique for implant-retained auricular prostheses. J. Prosthet. Dent. 1996, 75, 45-49. [CrossRef]

7. Gibson, I.; Rosen, D.; Stucker, B. Additive Manufacturing Technologies: 3D Printing, Rapid Prototyping, and Direct Digital Manufacturing, 2nd ed.; Springer: New York, NY, USA, 2015; ISBN 978-1-4939-2112-6.

8. Vandenbroucke, B.; Kruth, J.-P. Selective laser melting of biocompatible metals for rapid manufacturing of medical parts. Rapid Prototyp. J. 2007, 13, 196-203. [CrossRef]

9. 3D Printing Industry (3DPI). Arcam Announces FDA Clearance of Implants Produced with Additive Manufacturing. Available online: http:/ / www.arcam.com/arcam-announces-fda-clearance-of-implants-produced-with-additive-manufacturing (accessed on 31 March 2015).

10. Chua, C.K.; Wong, C.H.; Yeong, W.Y. Standards, Quality Control, and Measurement Sciences in 3D Printing and Additive Manufacturing; Academic Press: Cambridge, MA, USA, 2017; ISBN 978-0-12-813490-0.

11. Ameen, W.; Al-Ahmari, A.; Mohammed, M.K.; Abdulhameed, O.; Umer, U.; Moiduddin, K. Design, Finite Element Analysis (FEA), and fabrication of custom titanium alloy cranial implant using electron beam melting additive manufacturing. Adv. Produc. Engineer. Manag. 2018, 13, 267-278. [CrossRef]

12. Al-Ahmari, A.; Nasr, E.A.; Moiduddin, K.; Anwar, S.; Kindi, M.A.; Kamrani, A. A comparative study on the customized design of mandibular reconstruction plates using finite element method. Adv. Mech. Eng. 2015, 7. [CrossRef]

13. Ginestra, P.; Ferraro, R.M.; Zohar-Hauber, K.; Abeni, A.; Giliani, S.; Ceretti, E. Selective laser melting and electron beam melting of Ti6Al4V for orthopedic applications: A comparative study on the applied building direction. Materials 2020, 13, 5584. [CrossRef]

14. Murr, L.E.; Gaytan, S.M.; Martinez, E.; Medina, F.; Wicker, R.B. Next Generation Orthopaedic Implants by Additive Manufacturing Using Electron Beam Melting. Available online: https:/ /www.hindawi.com/journals/ijbm/2012/245727 (accessed on 3 February 2021).

15. Kotzem, D.; Ohlmeyer, H.; Walther, F. Damage tolerance evaluation of a unit cell plane based on Electron Beam Powder Bed Fusion (E-PBF) manufactured Ti6Al4V alloy. Procedia Struct. Integr. 2020, 28, 11-18. [CrossRef] 
16. Cheng, B.; Chou, K. Geometric consideration of support structures in part overhang fabrications by electron beam additive manufacturing. Comput. Aided Des. 2015, 69. [CrossRef]

17. Umer, U.; Ameen, W.; Abidi, M.H.; Moiduddin, K.; Alkhalefah, H.; Alkahtani, M.; Al-Ahmari, A. Modeling the effect of different support structures in electron beam melting of titanium alloy using finite element models. Metals 2019, 9, 806. [CrossRef]

18. Tran, T.Q.; Chinnappan, A.; Lee, J.K.Y.; Loc, N.H.; Tran, L.T.; Wang, G.; Kumar, V.V.; Jayathilaka, W.A.D.M.; Ji, D.; Doddamani, M.; et al. 3D printing of highly pure copper. Metals 2019, 9, 756. [CrossRef]

19. Shiomi, M.; Osakada, K.; Nakamura, K.; Yamashita, T.; Abe, F. Residual stress within metallic model made by selective laser melting process. CIRP Ann. 2004, 53, 195-198. [CrossRef]

20. Hussein, A.; Hao, L.; Yan, C.; Everson, R.; Young, P. Advanced lattice support structures for metal additive manufacturing. J. Mater. Process. Technol. 2013, 213, 1019-1026. [CrossRef]

21. Ameen, W.; Al-Ahmari, A.; Mohammed, M.; Mian, S. Manufacturability of overhanging holes using electron beam melting. Metals 2018, 8, 397. [CrossRef]

22. Wang, D.; Mai, S.; Xiao, D.; Yang, Y. Surface quality of the curved overhanging structure manufactured from 316-L stainless steel by SLM. Int. J. Adv. Manuf. Technol. 2016, 86, 781-792. [CrossRef]

23. Wang, D.; Yang, Y.; Zhang, M.; Lu, J.; Liu, R.; Xiao, D. Study on SLM fabrication of precision metal parts with overhanging structures. In Proceedings of the 2013 IEEE International Symposium on Assembly and Manufacturing (ISAM), Xi'an, China, 30 July-2 August 2013; pp. 222-225.

24. Ford, S.; Despeisse, M. Additive manufacturing and sustainability: An exploratory study of the advantages and challenges. $J$. Clean. Prod. 2016, 137, 1573-1587. [CrossRef]

25. Jiang, J.; Xu, X.; Stringer, J. Support structures for additive manufacturing: A review. J. Manuf. Mater. Process. 2018, 2, 64. [CrossRef]

26. Morgan, D.; Agba, E.; Hill, C. Support structure development and initial results for metal powder bed fusion additive manufacturing. Procedia Manuf. 2017, 10, 819-830. [CrossRef]

27. Samant, R.; Ranjan, R.; Mhapsekar, K.; Anand, S. Octree data structure for support accessibility and removal analysis in additive manufacturing. Addit. Manuf. 2018, 22, 618-633. [CrossRef]

28. Jhabvala, J.; Boillat, E.; André, C.; Glardon, R. An innovative method to build support structures with a pulsed laser in the selective laser melting process. Int. J. Adv. Manuf. Technol. 2012, 59, 137-142. [CrossRef]

29. Yan, C.; Hao, L.; Hussein, A.; Raymont, D. Evaluations of cellular lattice structures manufactured using selective laser melting. Int. J. Mach. Tools Manuf. 2012, 62, 32-38. [CrossRef]

30. Park, S.; Rosen, D.; Duty, C. Comparing mechanical and geometrical properties of lattice structure fabricated using electron beam melting. In Proceedings of the 2014 Annual International Solid Freeform Fabrication Symposium-An Additive Manufacturing Conference, Austin, TX, USA, 6 August 2014; Volume 1, pp. 1359-1370.

31. Li, Z.; Zhang, D.Z.; Dong, P.; Kucukkoc, I. A lightweight and support-free design method for selective laser melting. Int. J. Adv. Manuf. Technol. 2017, 90, 2943-2953. [CrossRef]

32. Langelaar, M. Topology optimization of 3D self-supporting structures for additive manufacturing. Addit. Manuf. 2016, 12, 60-70. [CrossRef]

33. Calignano, F. Design optimization of supports for overhanging structures in aluminum and titanium alloys by selective laser melting. Mater. Des. 2014, 64, 203-213. [CrossRef]

34. Ruffo, M.; Tuck, C.; Hague, R. Cost estimation for rapid manufacturing-laser sintering production for low to medium volumes. Proc. Inst. Mech. Eng. Part B 2006, 220, 1417-1427. [CrossRef]

35. Hopkinson, N.; Dicknes, P. Analysis of rapid manufacturing-Using layer manufacturing processes for production. Proc. Inst. Mech. Eng. Part C 2003, 217, 31-39. [CrossRef]

36. Syam, W.; Al-Ahmari, A.; Mannan, M.; Al-Shehri, H.; Al-Wazzan, K. Metallurgical, accuracy and cost analysis of Ti6Al4V dental coping fabricated by electron beam melting process. In Proceedings of the 5th International Conference on Advanced Research in Virtual and Rapid Prototyping, Leiria, Portugal, 28 September-1 October 2011; ISBN 978-0-415-68418-7.

37. Lindemann, C.; Jahnke, U.; Habdank, M.; Koch, R. Analyzing product lifecycle costs for a better understanding of cost drivers in additive manufacturing. In Proceedings of the 23th Annual International Solid Freeform Fabrication Symposium-An Additive Manufacturing Conference, Austin, TX, USA, 6-8 August 2012.

38. Baumers, M.; Dickens, P.; Tuck, C.; Hague, R. The cost of additive manufacturing: Machine productivity, economies of scale and technology-push. Technol. Forecast. Soc. Chang. 2016, 102, 193-201. [CrossRef]

39. Priarone, P.C.; Robiglio, M.; Ingarao, G.; Settineri, L. Assessment of cost and energy requirements of Electron Beam Melting (EBM) and machining processes. In International Conference on Sustainable Design and Manufacturing, Bologna, Italy, 26-28 April 2017; Campana, G., Howlett, R.J., Setchi, R., Cimatti, B., Eds.; Smart Innovation, Systems and Technologies; Springer: Cham, Switzerland, 2017; Volume 68, pp. 723-735. ISBN 978-3-319-57077-8.

40. Choi, J.-Y.; Choi, J.-H.; Kim, N.-K.; Kim, Y.; Lee, J.-K.; Kim, M.-K.; Lee, J.-H.; Kim, M.-J. Analysis of errors in medical rapid prototyping models. Int. J. Oral Maxillofac. Surg. 2002, 31, 23-32. [CrossRef]

41. Mostafa Elkatatny, A.A.A.; Eldabaa, K.A. Cranioplasty: A new perspective. Open Access Maced. J. Med. Sci. 2019, 7, $2093-2101$. [CrossRef] [PubMed] 
42. Höhne, J.; Brawanski, A.; Gassner, H.; Schebesch, K.-M. Feasibility of the custom-made titanium cranioplasty CRANIOTOP ${ }^{\circledR}$. Surg. Neurol. Int. 2013, 4, 88. [CrossRef] [PubMed]

43. Brown, D.A.; Wijdicks, E.F.M. Decompressive craniectomy in acute brain injury. Handb. Clin. Neurol. 2017, 140, 299-318. [CrossRef] [PubMed]

44. Toth, B.A.; Ellis, D.S.; Stewart, W.B.; Jeffrey, L.; Marsh, D.; Vannier, M.W. Computer-designed prostheses for orbitocranial reconstruction. Plast. Reconstr. Surg. 1988, 81, 323-3241. [CrossRef]

45. Joffe, J.M.; McDermott, P.J.; Linney, A.D.; Mosse, C.A.; Harris, M. Computer-generated titanium cranioplasty: Report of a new technique for repairing skull defects. Br. J. Neurosurg. 1992, 6, 343-350. [CrossRef]

46. Webb, P.A. A Review of Rapid Prototyping (RP) techniques in the medical and biomedical sector. J. Med. Eng. Technol. 2000, 24, 149-153. [CrossRef]

47. Moreira-Gonzalez, A.; Jackson, I.T.; Miyawaki, T.; Barakat, K.; DiNick, V. Clinical outcome in cranioplasty: Critical review in long-term follow-up. J. Craniofac. Surg. 2003, 14, 144-153. [CrossRef]

48. Maravelakis, E.; David, K.; Antoniadis, A.; Manios, A.; Bilalis, N.; Papaharilaou, Y. Reverse engineering techniques for cranioplasty: A case study. J. Med. Eng. Technol. 2008, 32, 115-121. [CrossRef]

49. Moiduddin, K.; Hammad Mian, S.; Umer, U.; Ahmed, N.; Alkhalefah, H.; Ameen, W. Reconstruction of complex zygomatic bone defects using mirroring coupled with EBM fabrication of titanium implant. Metals 2019, 9, 1250. [CrossRef]

50. Alsing, L.; Storm, S.J. Sustainability of Additive Manufacturing-Electron Beam Melting of IN718. Ph.D. Thesis, University West, Trollhättan, Sweden, 2019.

51. Arcam A2 Setting the Standard for Additive Manufacturing. Available online: http://www.arcam.com/wp-content/uploads/ Arcam-A2.pdf (accessed on 12 July 2019). 